\title{
Nanostructured Amorphous Silicas Hydrophobized by Various Pathways
}

Iryna S. Protsak ${ }^{\mathrm{a}, \mathrm{b}}$, Volodymyr M. Gun'koc ${ }^{\mathrm{c}}$ Ian M. Henderson ${ }^{\mathrm{d}}$, Evgeniy M. Pakhlov,

Dariusz Sternik ${ }^{\mathrm{e}}$, Zichun Le $\mathrm{e}^{\mathrm{b}, *}$

\begin{abstract}
${ }^{a}$ College of Environment, Zhejiang University of Technology, Hangzhou 310014, China
${ }^{b}$ College of Science, Zhejiang University of Technology, Hangzhou 310023, China

${ }^{c}$ Chuiko Institute of Surface Chemistry of NAS of Ukraine, Kiev 03164, Ukraine

${ }^{d}$ Omphalos Bioscience, LLC, Albuquerque 87110, NM, USA

'Maria Curie-Sklodowska University, Lublin 20-031, Poland
\end{abstract}

*Corresponding author: Zichun Le (e-mail address: 1zc@zjut.edu.cn)

\section{Samples}

PDMS

Approximation based on data for the viscosity range $\eta=0.65-6 \times 10^{4} \mathrm{~mm}^{2} / \mathrm{s}, 25{ }^{\circ} \mathrm{C},{ }^{1}$ could be used to estimate the molecular weight ( $M W$ in $\mathrm{g} / \mathrm{mol}) v s$. the PDMS viscosity that gives the $M W$ values of ca. 815, 6004, 9670, 28000, and 67700 g/mol for PMS5, PMS100, PMS200, PMS1000, and PMS12500, respectively. These values correspond to the degree of PDMS polymerization of ca. $11,81,131,378$, and 914 , respectively.

Table S1. Studied samples

\begin{tabular}{|l|l|c|c|c|}
\hline No & Samples & Label & $\begin{array}{c}C_{\mathrm{C}} \\
\text { (wt.\%) }\end{array}$ & $\begin{array}{c}C_{\mathrm{H}} \\
\text { (wt.\%) }\end{array}$ \\
\hline 1 & A-300 & A & & \\
\hline 2 & A-300/PMS5 $(10: 4 \mathrm{~g} / \mathrm{g}) 250^{\circ} \mathrm{C}$ for $1 \mathrm{~h}$ & AP1 & 9.12 & 2.276 \\
\hline 3 & A-300/PMS100/DMC $(10: 2: 2) 200^{\circ} \mathrm{C}$ for $1 \mathrm{~h}$ & AP2D & 5.55 & 1.457 \\
\hline 4 & A-300/PMS1000/DMC $(10: 2: 2) 220^{\circ} \mathrm{C}$ for $1 \mathrm{~h}$ & AP4D & 2.86 & 0.877 \\
\hline 5 & A-300/PMS12500/DMC $(10: 2: 2) 200^{\circ} \mathrm{C}$ for $1 \mathrm{~h}$ & AP5D & 3.32 & 0.969 \\
\hline 6 & cA-300 & cA & & \\
\hline 7 & cA-300/PMS200/DMC $(20: 4: 4) 220^{\circ} \mathrm{C}$ for $1 \mathrm{~h}$ & cAP3D & 5.42 & 1.589 \\
\hline 8 & cA-300/HMDS $(20 \mathrm{~g} / 10.5 \mathrm{~mL}) 80^{\circ} \mathrm{C}$ for $1.5 \mathrm{~h}$ & cAH & 3.33 & 0.965 \\
\hline 9 & A300 & AE & & \\
\hline 10 & A300/PMS5 $(10: 4 \mathrm{~g} / \mathrm{g}) 250^{\circ} \mathrm{C}$ for $1 \mathrm{~h}$ & AEP1 & 8.21 & 2.033 \\
\hline 11 & A300/PMS100/DMC $(10: 2: 2) 200^{\circ} \mathrm{C}$ for $1 \mathrm{~h}$ & AEP2D & 3.53 & 1.083 \\
\hline 12 & A300/PMS1000/DMC $(10: 2: 2) 200^{\circ} \mathrm{C}$ for $1 \mathrm{~h}$ & AEP4D & 3.05 & 0.979 \\
\hline 13 & TS 100 & T & & \\
\hline 14 & TS100/PMS200/DMC $(10: 2: 2) 200^{\circ} \mathrm{C}$ for $1 \mathrm{~h}$ & TP3D & 4.9 & 1.503 \\
\hline 15 & Syloid 244 & S & & \\
\hline 16 & Syloid244/PMS200/DMC $(10: 2: 2) 200^{\circ} \mathrm{C}$ for $1 \mathrm{~h}$ & SP3D & 5.05 & 1.527 \\
\hline
\end{tabular}

Note. The bulk density $\left(\rho_{\mathrm{b}}\right)$ of modified samples changes insignificantly, e.g., $\rho_{\mathrm{b}}=0.047,0.056,0.047,0.050 \mathrm{~g} / \mathrm{cm}^{3}$ for A-300, cAP3D, AP4D, and AP5D, respectively. CHN analysis was carried out only for modified silicas. 


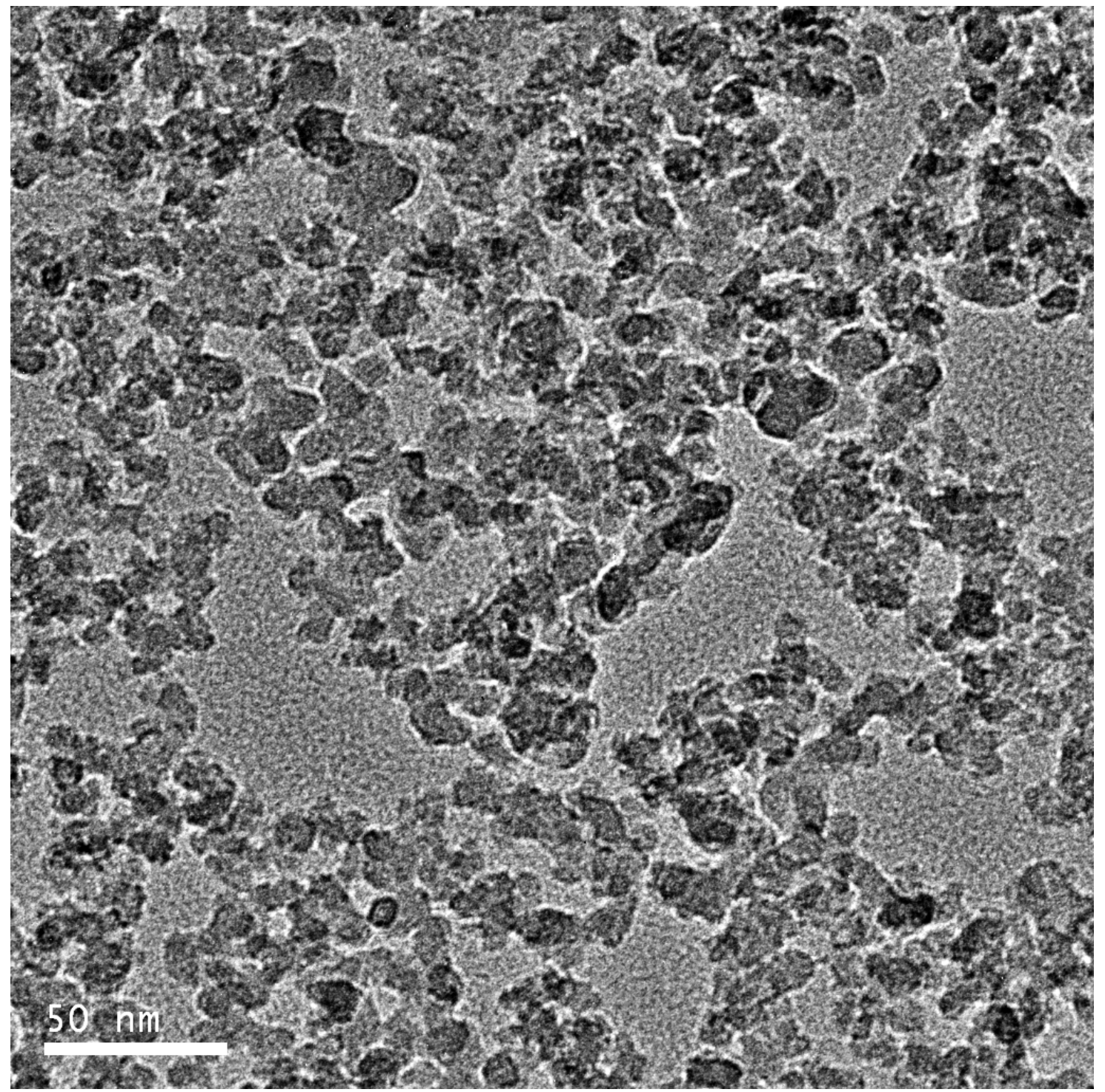

Figure S1. TEM image of cA-300/HMDS. 

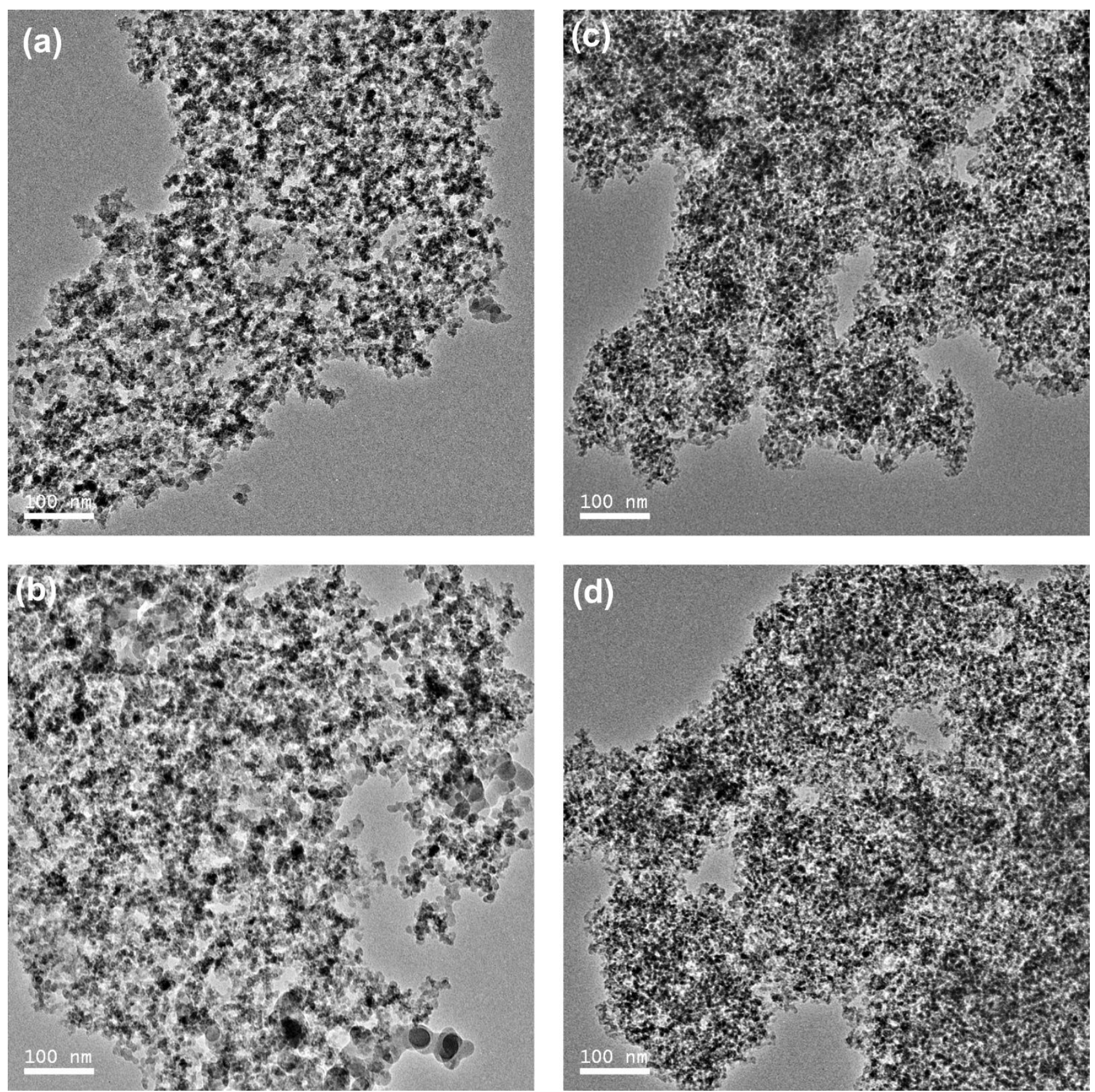

Figure S2. TEM images of TS 100 (a) unmodified and (b) modified (TP3D), and Syloid 244 (c) unmodified and (d) modified (SP3D). 
(a)

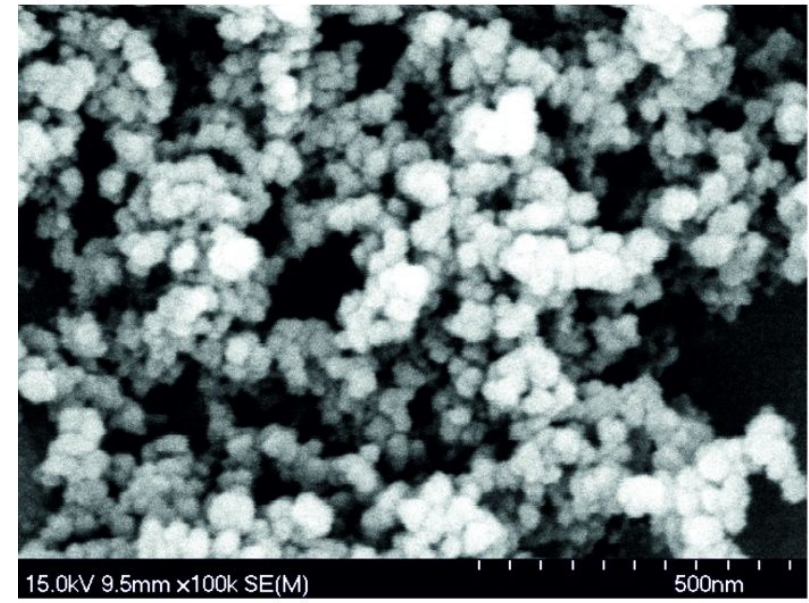

(c)

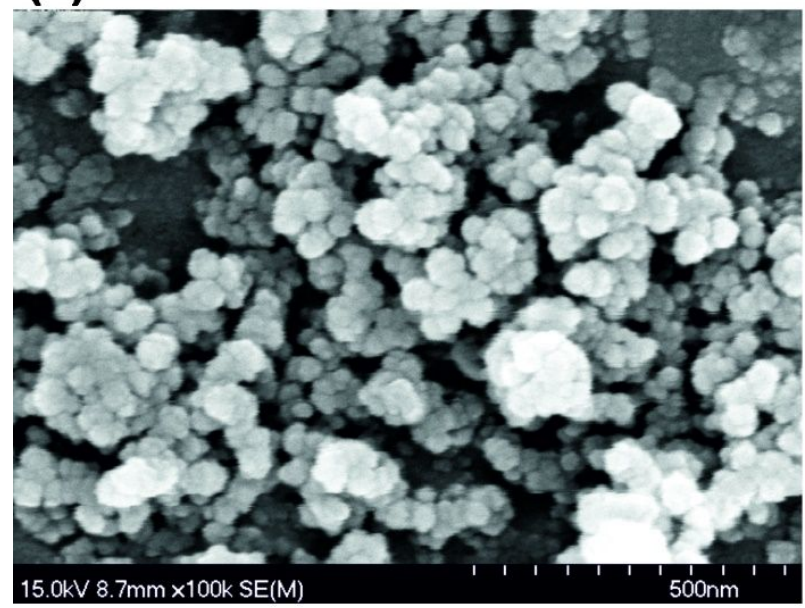

(b)

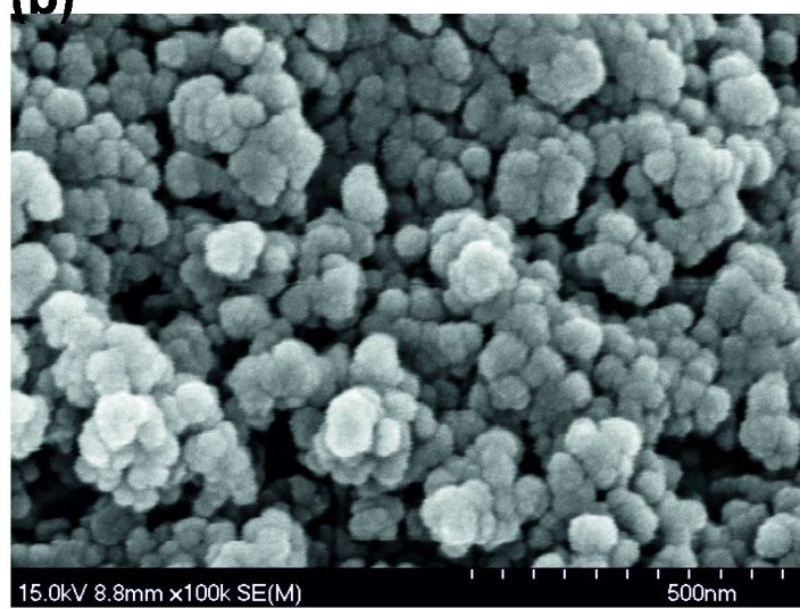

(d)

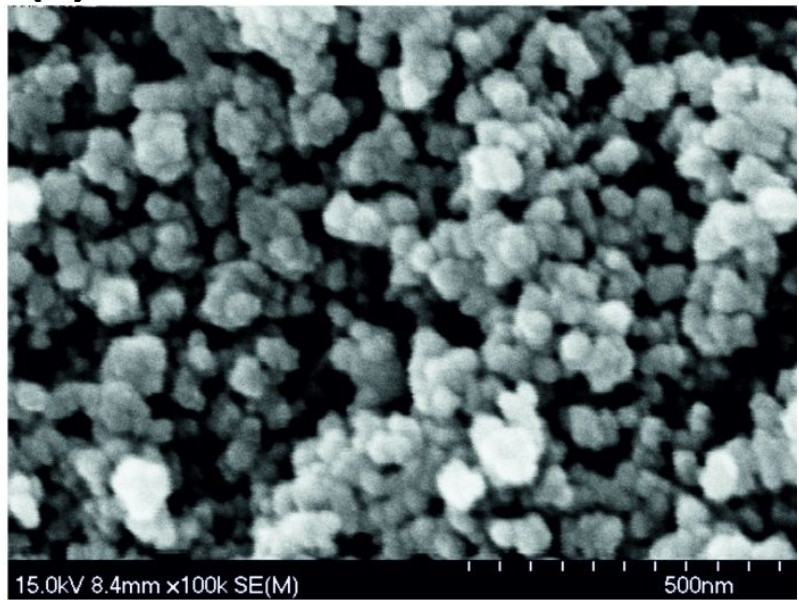

(e)

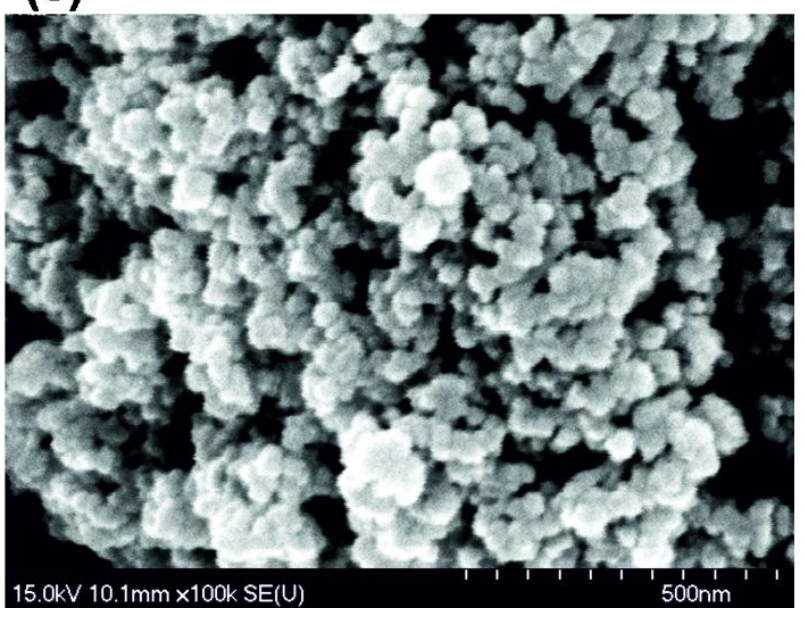

Figure S3. SEM images of A-300 (a) unmodified and (b-e) modified (b) AP1, (c) AP2D, (d) AP4D, and (e) AP5D. 
(a)

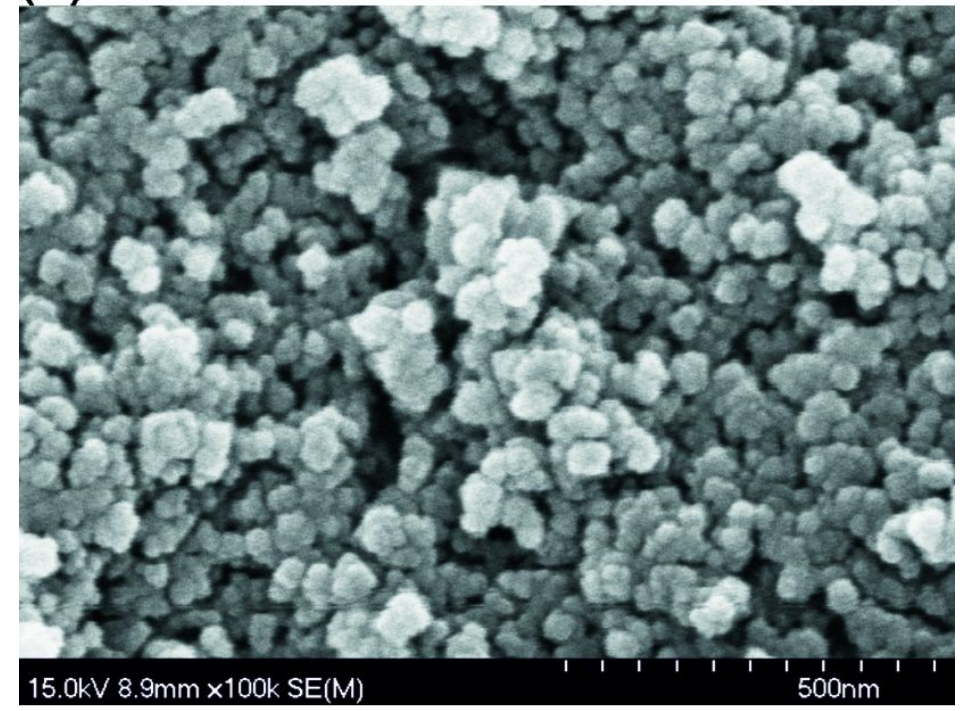

(b)

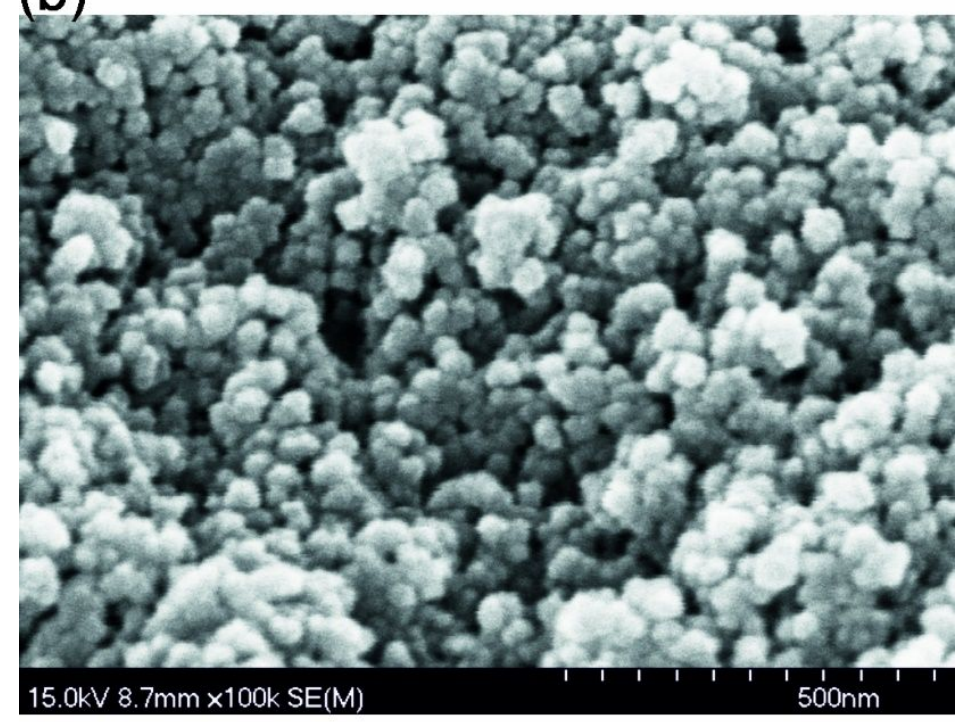

(c)

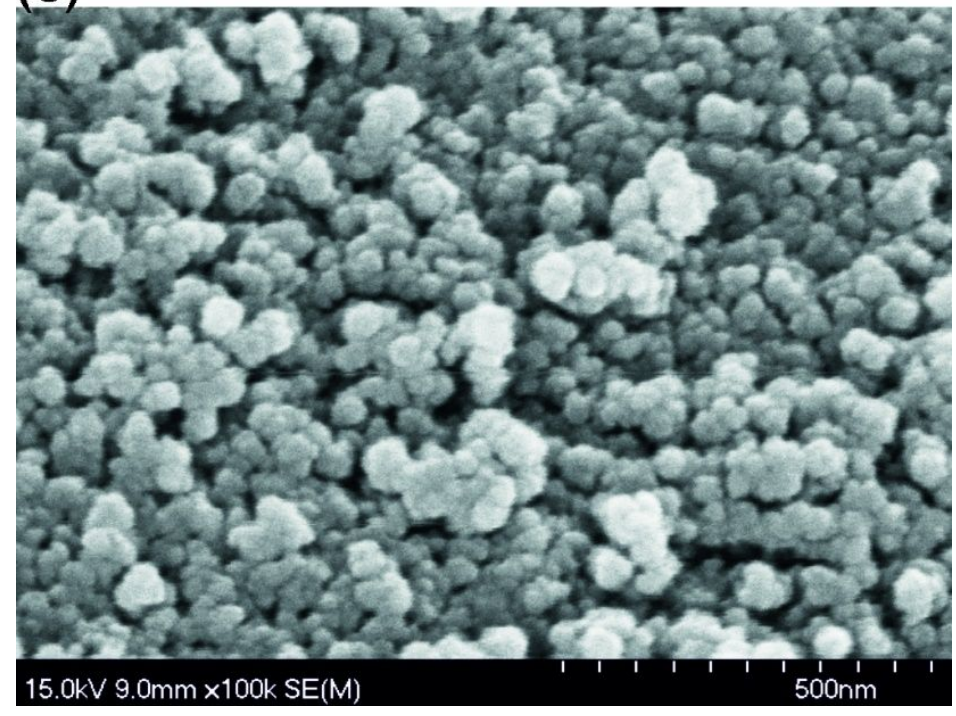

Figure S4. SEM images of cA-300 (a) unmodified and modified (b) cAP3D, and (c) cAH. 
(a)

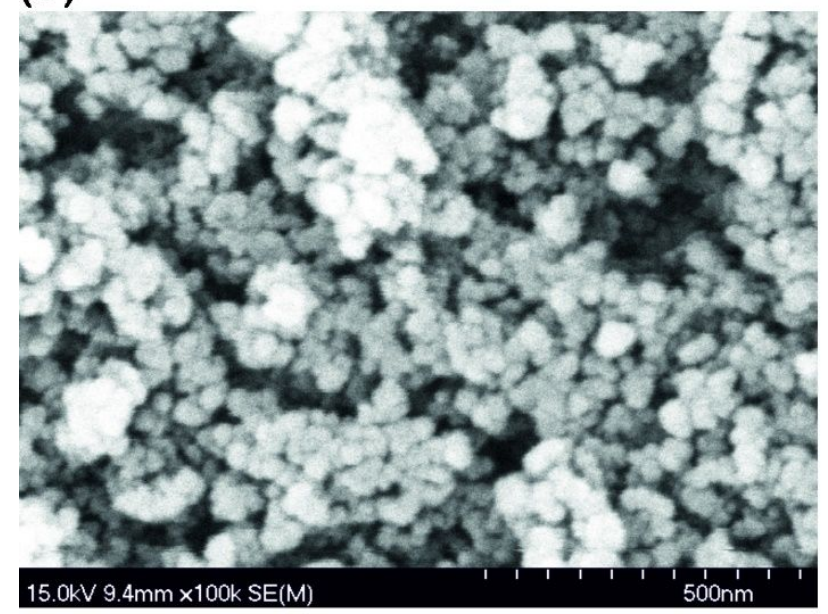

(c)

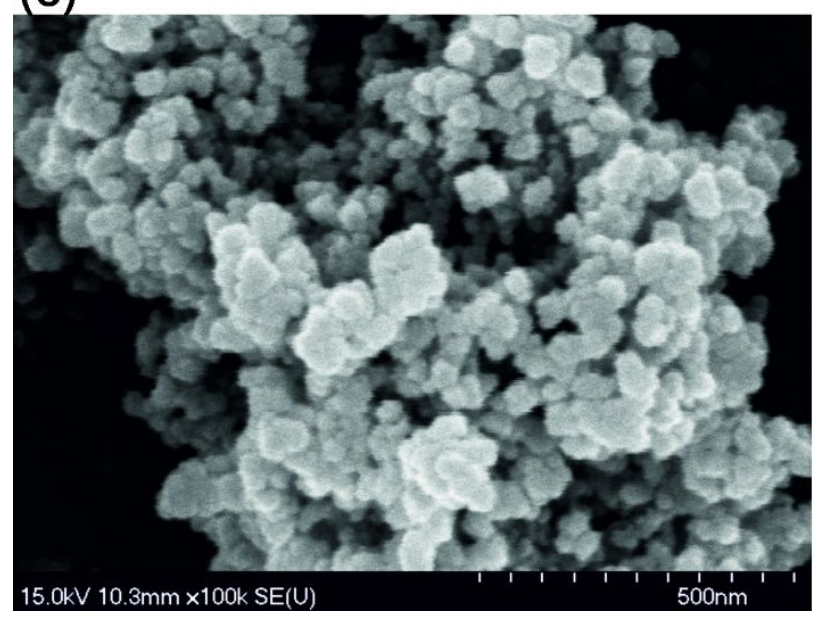

(b)

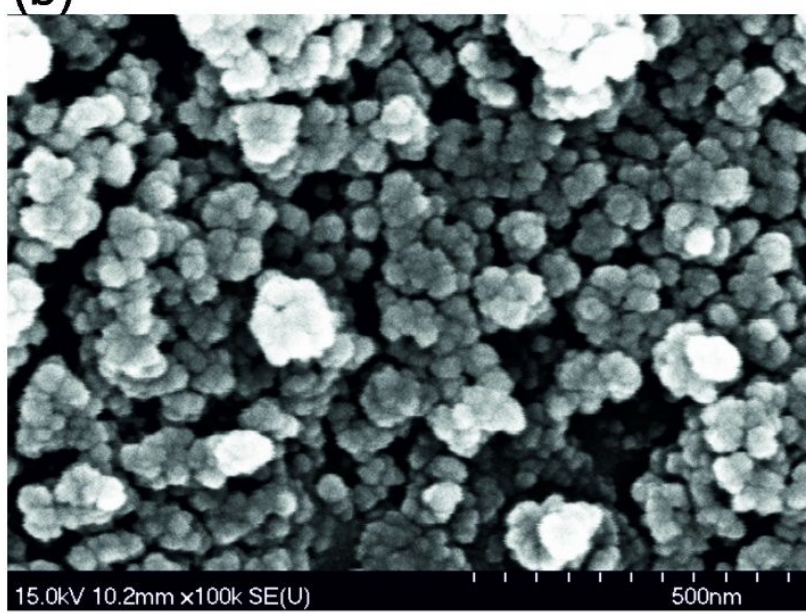

(d)

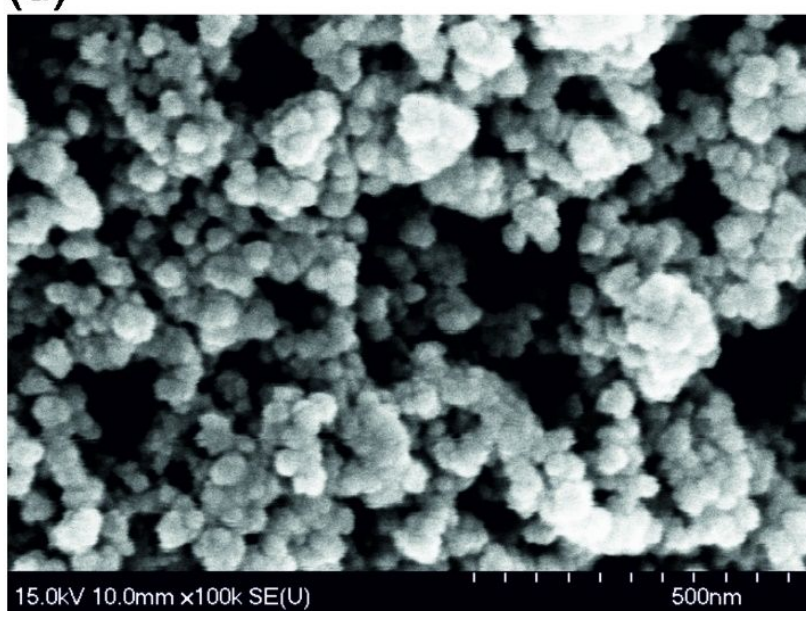

Figure S5. SEM images of A300 (a) unmodified (AE) and (b-d) modified (b) AEP1, (c) AEP2D, and (d) AEP4D. 
(a)

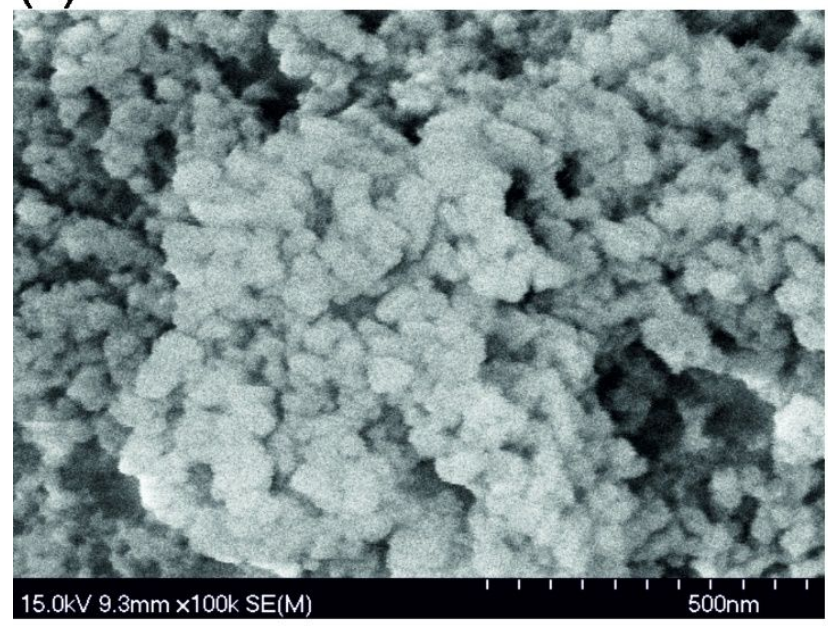

(b)

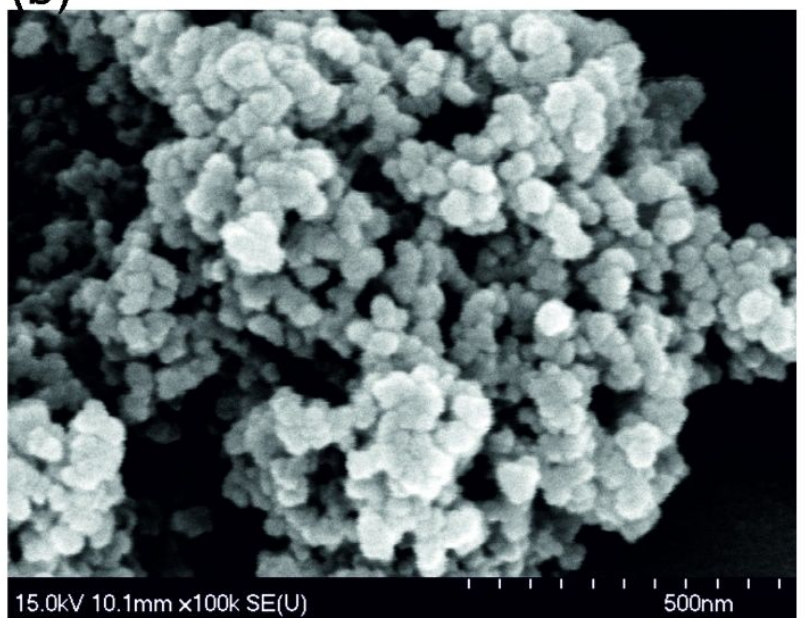

(c)

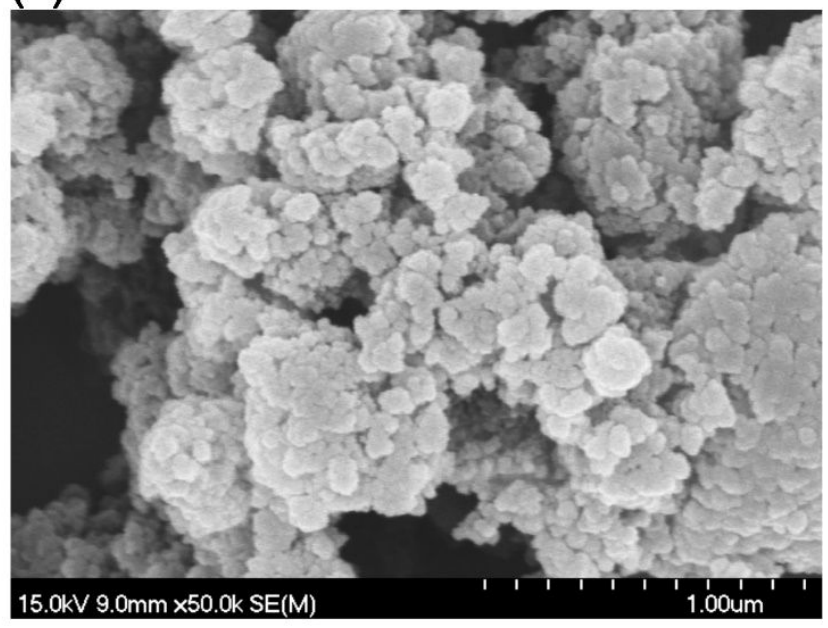

(d)

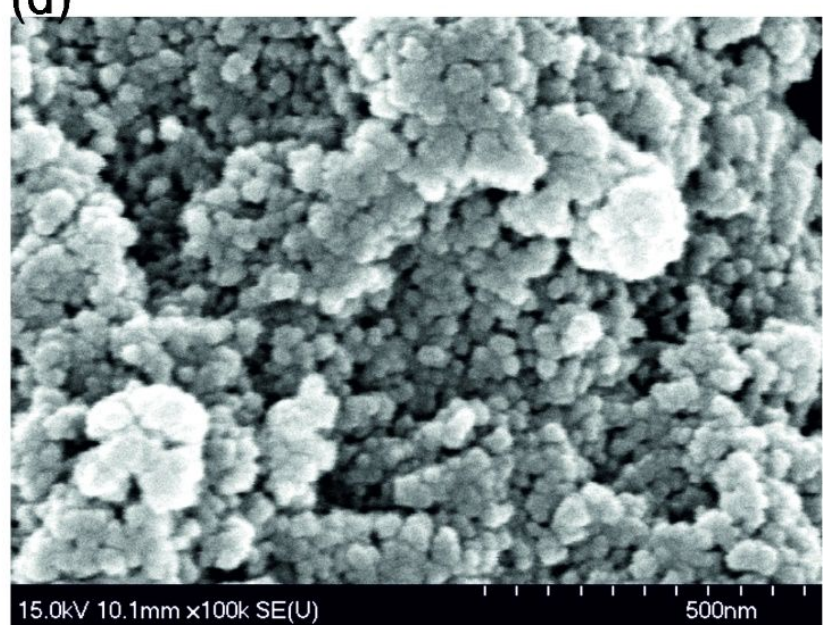

Figure S6. SEM images of TS 100 (a) unmodified and (b) modified (TP3D), and Syloid 244 (c) unmodified and (d) modified (SP3D).

\section{Textural characteristics}

The total pore volume was estimated from nitrogen adsorption at $\mathrm{p} / \mathrm{p}_{0} \approx 0.98-0.99$, where $\mathrm{p}$ and $\mathrm{p}_{0}$ denote the equilibrium and saturation pressure of nitrogen at $77.4 \mathrm{~K}$, respectively. ${ }^{2}$ The nitrogen desorption data were used to calculate the pore-size distributions (PSD, differential $\mathrm{f}_{\mathrm{V}}(\mathrm{R}) \sim$ $\mathrm{dV}_{\mathrm{p}} / \mathrm{dR}$ and $\left.\mathrm{f}_{\mathrm{S}}(\mathrm{R}) \sim \mathrm{dS} / \mathrm{dR}\right)$ using a regularization procedure under non-negativity condition $\left(\mathrm{f}_{\mathrm{V}}(\mathrm{R})\right.$ $\geq 0$ at any pore radius $\mathrm{R}$ ) at a fixed regularization parameter $\alpha=0.01 .{ }^{3}$ A pore model with voids between spherical NPNP packed in random aggregates (ANPNP) was applied using the parameters corresponding to silica. ${ }^{3}$ The PSD calculations were based on the density functional theory (DFT) approach described by the authors ${ }^{4}$ for carbons and modified to study various adsorbents including silica and polymers. ${ }^{3}$ The differential PSD with respect to the pore volume $f_{V}(R) \sim d V / d R, \int f_{V}(R) d R$ $\sim \mathrm{V}_{\mathrm{p}}$ were re-calculated to incremental PSD (IPSD) (Fig. 4) at $\Phi_{\mathrm{V}}\left(\mathrm{R}_{\mathrm{i}}\right)=\left(\mathrm{f}_{\mathrm{V}}\left(\mathrm{R}_{\mathrm{i}+1}\right)+\mathrm{f}_{\mathrm{V}}\left(\mathrm{R}_{\mathrm{i}}\right)\right)\left(\mathrm{R}_{\mathrm{i}+1}-\right.$ $\left.\mathrm{R}_{\mathrm{i}}\right) / 2$ giving $\sum \Phi_{\mathrm{V}}\left(\mathrm{R}_{\mathrm{i}}\right)=\mathrm{V}_{\mathrm{p}}$. The $\mathrm{f}_{\mathrm{V}}(\mathrm{R})$ and $\mathrm{f}_{\mathrm{S}}(\mathrm{R})$ functions ${ }^{3}$ were also used to calculate the 
contributions of nanopores $\left(\mathrm{V}_{\text {nano }}\right.$ and $\mathrm{S}_{\text {nano }}$ at $\left.0.35 \mathrm{~nm}<\mathrm{R}<1 \mathrm{~nm}\right)$, mesopores $\left(\mathrm{V}_{\text {meso }}\right.$ and $\mathrm{S}_{\text {meso }}$ at 1 $\mathrm{nm}<\mathrm{R}<25 \mathrm{~nm}$ ), and macropores $\left(\mathrm{V}_{\text {macro }}\right.$ and $\mathrm{S}_{\text {macro }}$ at $25 \mathrm{~nm}<\mathrm{R}<100 \mathrm{~nm}$ ) (Table 1). The values of $\left\langle\mathrm{R}_{\mathrm{V}}>\right.$ and $<\mathrm{R}_{\mathrm{S}}>$ (Table 1) as the average pore radii were calculated as a ratio of the first moment of $f_{V}(R)$ or $f_{S}(R)$ to the zero moment (integration was done over the $0.35-100 \mathrm{~nm}$ range) $<\mathrm{R}>=$ $\int \mathrm{f}(\mathrm{R}) \mathrm{RdR} / \mathrm{f}(\mathrm{R}) \mathrm{dR}$. Moreover, a non-local DFT (NLDFT, Quantachrome software, with a model of cylindrical pores in silica) method was used to calculate the differential PSD as dV/dR (Fig. S8).

It should be noted that the value of $V_{\mathrm{p}}$ (Table 1$)$ is much lower than the empty volume $\left(V_{\mathrm{em}}\right.$ $=1 / \rho_{\mathrm{b}}-1 / \rho_{0}$, where $\rho_{\mathrm{b}}$ and $\rho_{0}$ are the bulk and true densities of samples) in the NAS powder, since $V_{\text {em }}$ can reach $20.7 \mathrm{~cm}^{3} / \mathrm{g}$ for A-300 at $\rho_{\mathrm{b}} \approx 0.0473 \mathrm{~g} / \mathrm{cm}^{3}$, but the value of $V_{\mathrm{p}}$ is typically smaller than $1 \mathrm{~cm}^{3} / \mathrm{g}$. This underestimation of the value of $V_{\mathrm{p}}$ calculated from the nitrogen adsorption is due to very weak influence of the pore walls (nanoparticle surface) on the nitrogen molecules located in macropores far from the solid surface in loose NAS agglomerates. 

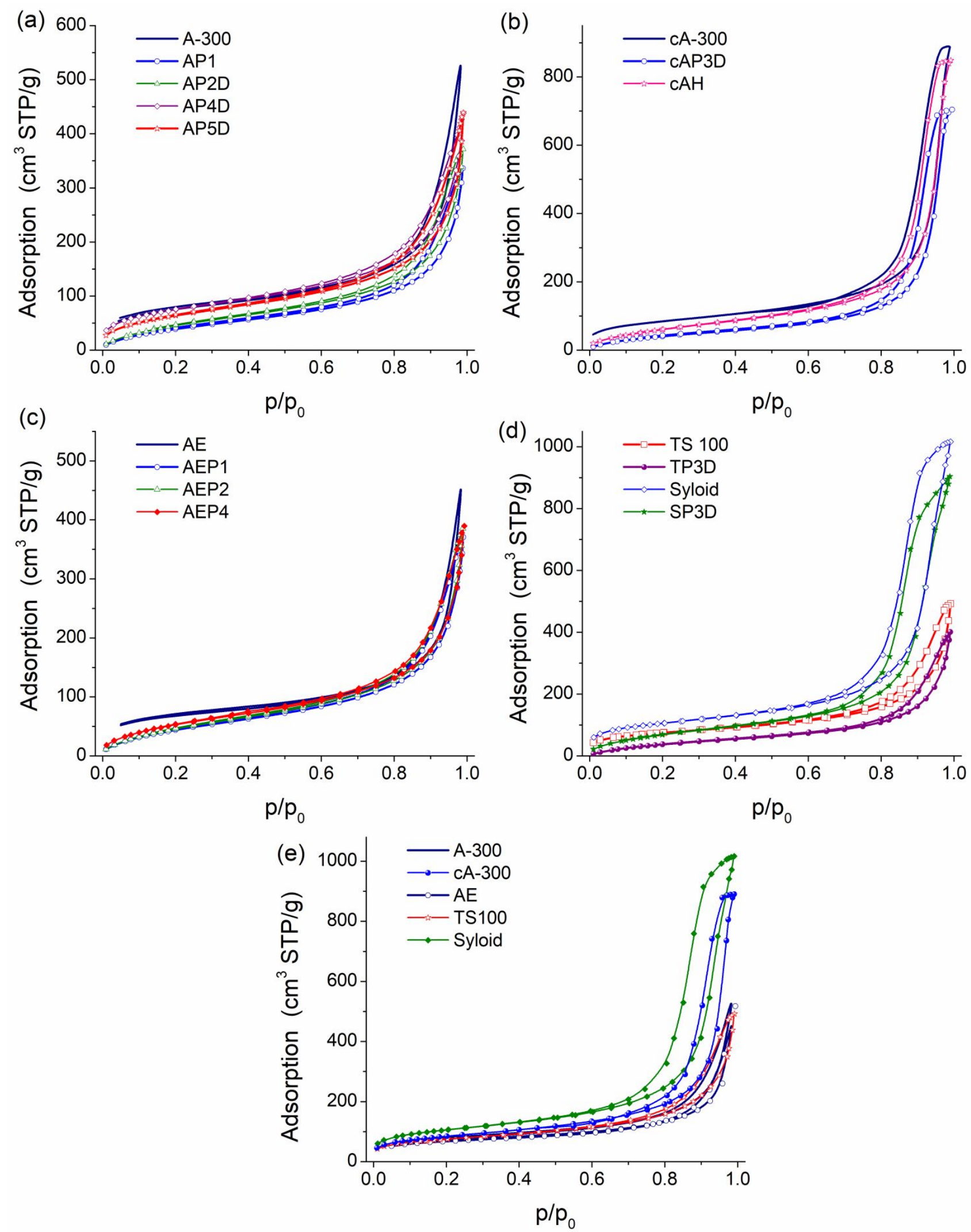

Figure S7. Nitrogen adsorption-desorption isotherms (77.35 K) for (a) A-300 unmodified and modified, (b) cA-300 unmodified and modified, (c) A300 (AE) unmodified and modified, (d) TS 100 and Syloid 244 unmodified and modified, (e) unmodified silicas. 

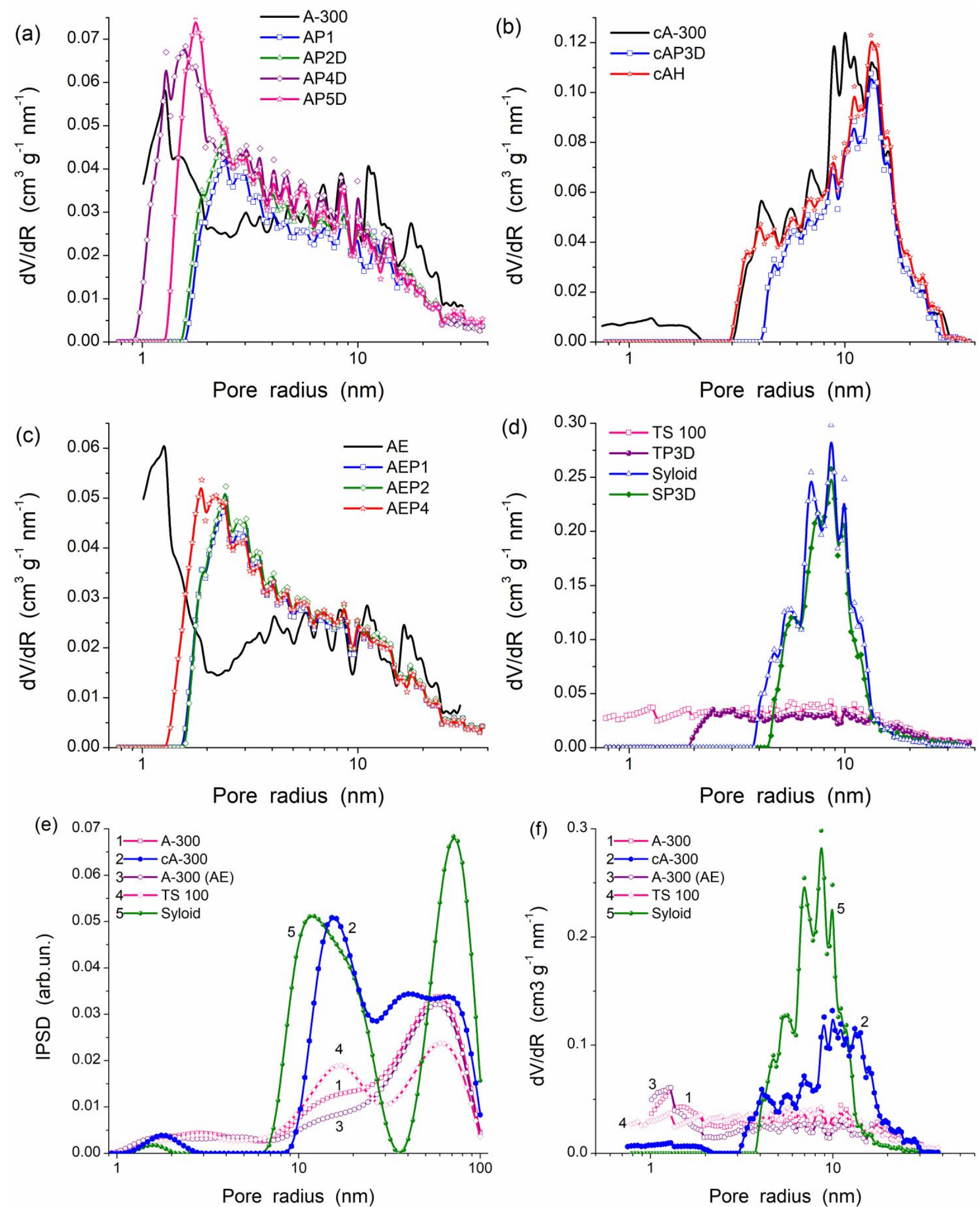

Figure S8. Differential pore size distribution calculated using the nitrogen ads-des isotherms treated with the NLDFT method (a-d,f) with a model of cylindrical pores in silica) for (a) A-300 unmodified and modified, (b) cA-300 unmodified and modified, (c) A300 (AE) unmodified and modified, (d) TS 100 and Syloid 244 unmodified and modified; (e) incremental and (f) differential PSD of unmodified NAS with pore models as (e) voids between silica NPNP and cylindrical pores in silica. 

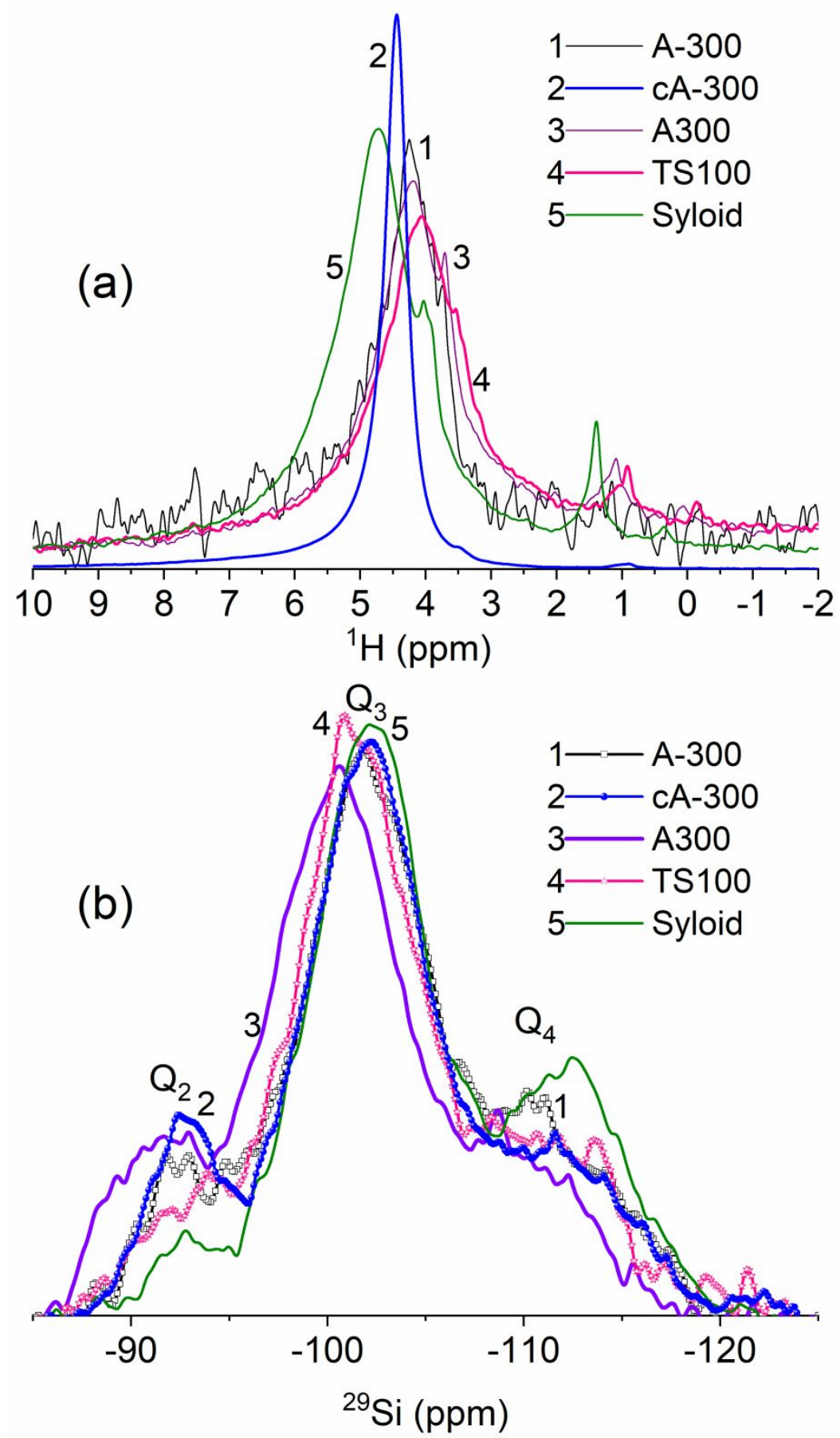

Figure S9. (a) ${ }^{1} \mathrm{H}$ MAS and (b) ${ }^{29} \mathrm{Si} \mathrm{CP} / \mathrm{MAS}$ NMR spectra of unmodified silicas studied. 
(a)

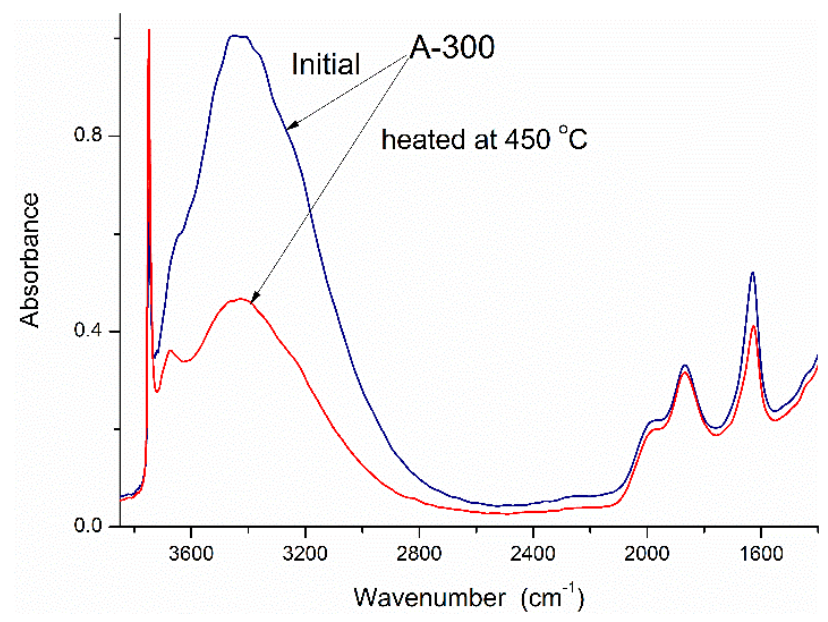

(b)

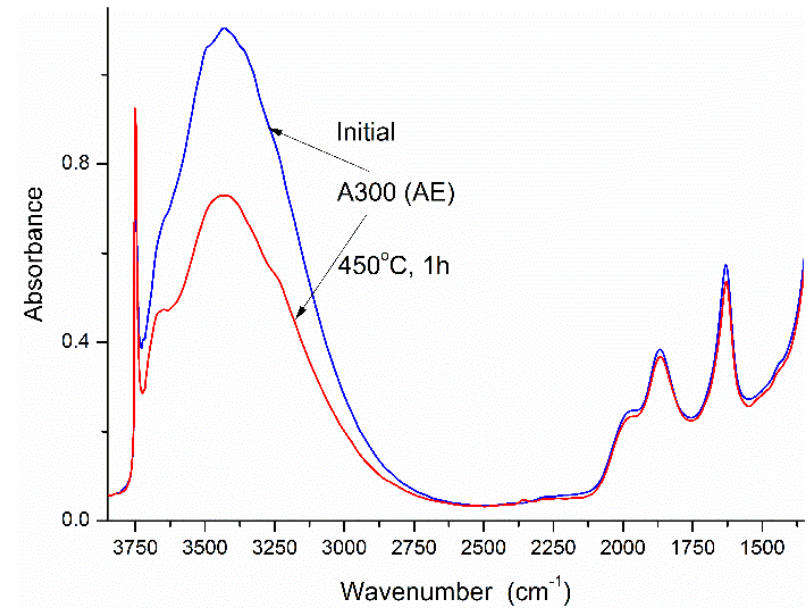

Figure S10. The IR spectra (in the $3800-1350 \mathrm{~cm}^{-1}$ range) of (a) A-300 and (b) A-300 (AE) initial and after heating at $450^{\circ} \mathrm{C}$ for $1 \mathrm{~h}$. 
(a)

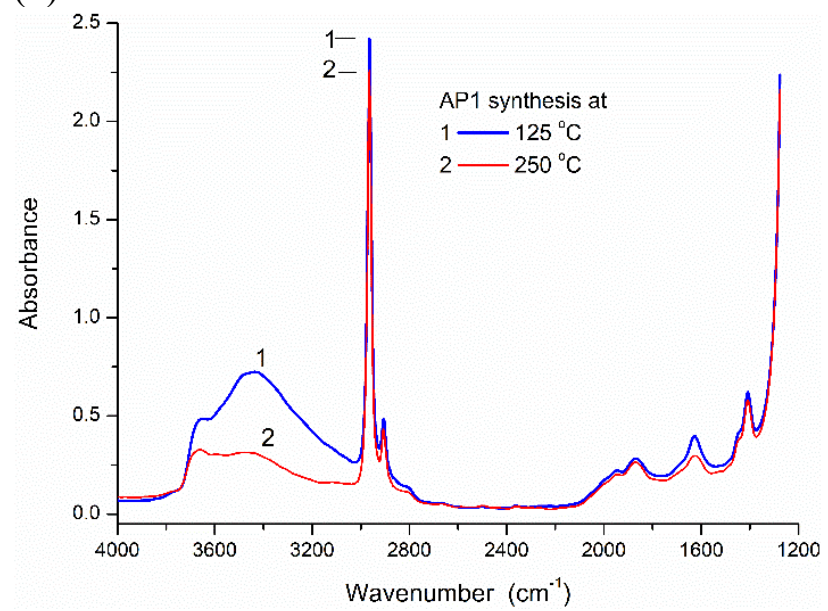

(c)

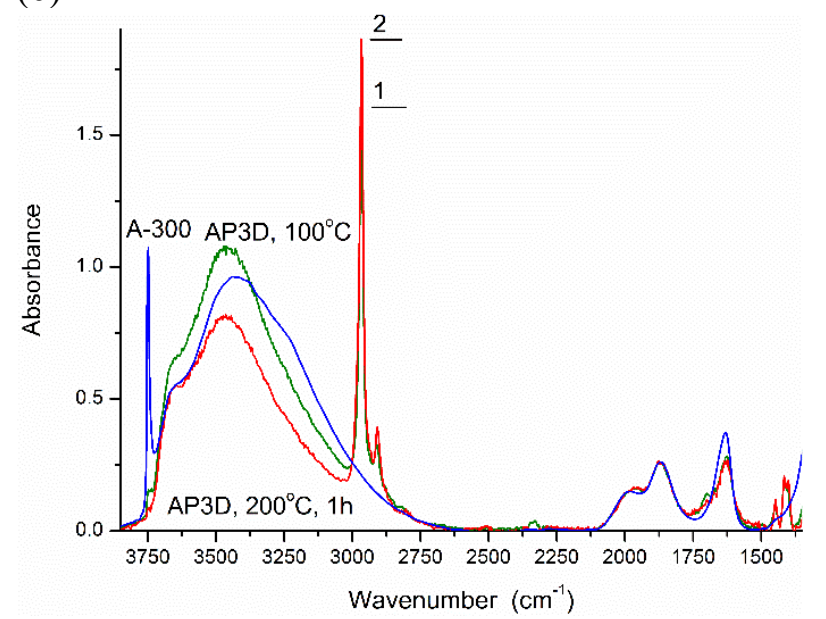

(e)

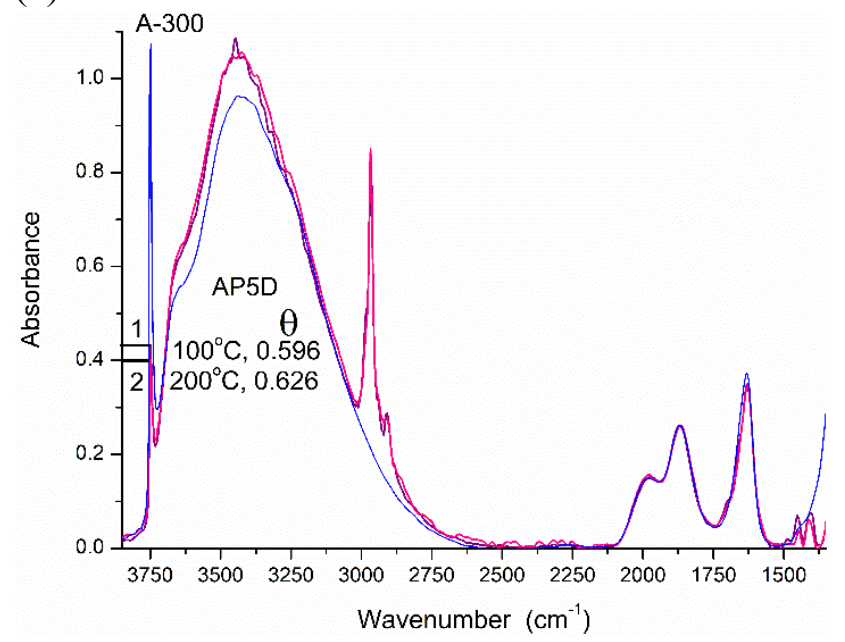

(b)

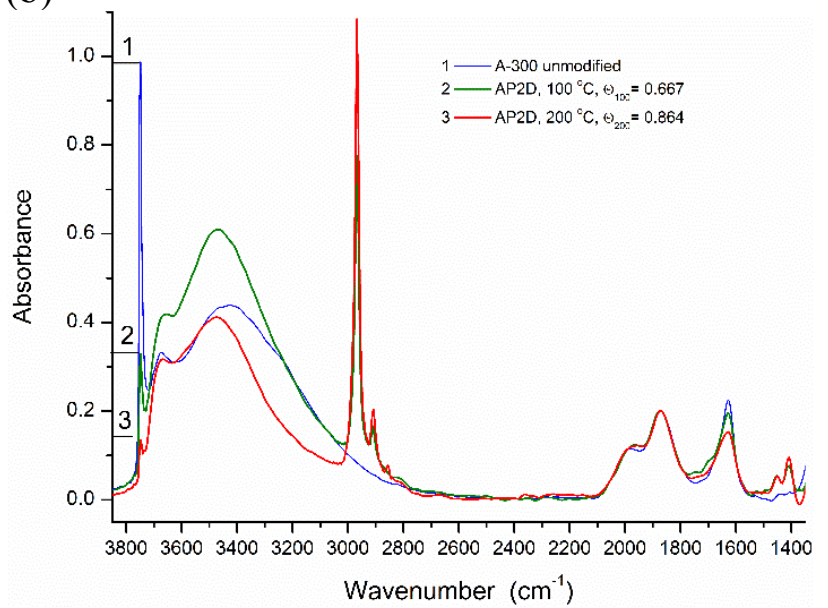

(d)

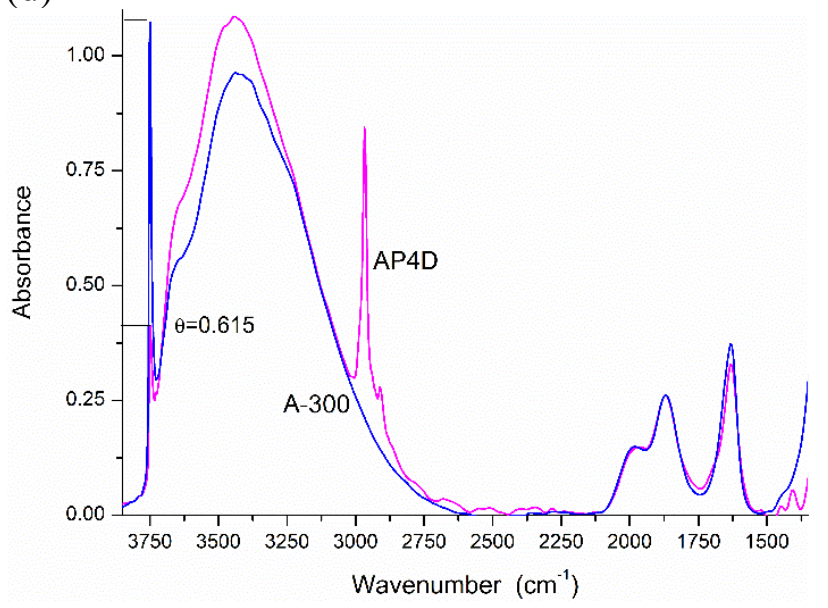

Figure S11. The IR spectra (in the $3800-1350 \mathrm{~cm}^{-1}$ range) of A-300 modified by (a) P1 at $125^{\circ} \mathrm{C}$ and $250{ }^{\circ} \mathrm{C}$; (b) P2D at $100{ }^{\circ} \mathrm{C}$ and $200{ }^{\circ} \mathrm{C}$; (c) P3D at $100{ }^{\circ} \mathrm{C}$ and $200{ }^{\circ} \mathrm{C}$; (d) P4D at $200{ }^{\circ} \mathrm{C}$; and (e) P5D at $100{ }^{\circ} \mathrm{C}$ and $200{ }^{\circ} \mathrm{C}$ for $1 \mathrm{~h}$. In some Figures, the values of $\theta$ (the degree of substitution of free silanols (band at $3750-3740 \mathrm{~cm}^{-1}$ ) by hydrophobic functionalities) are shown as the spectra of unmodified silica A-300. 
(a)

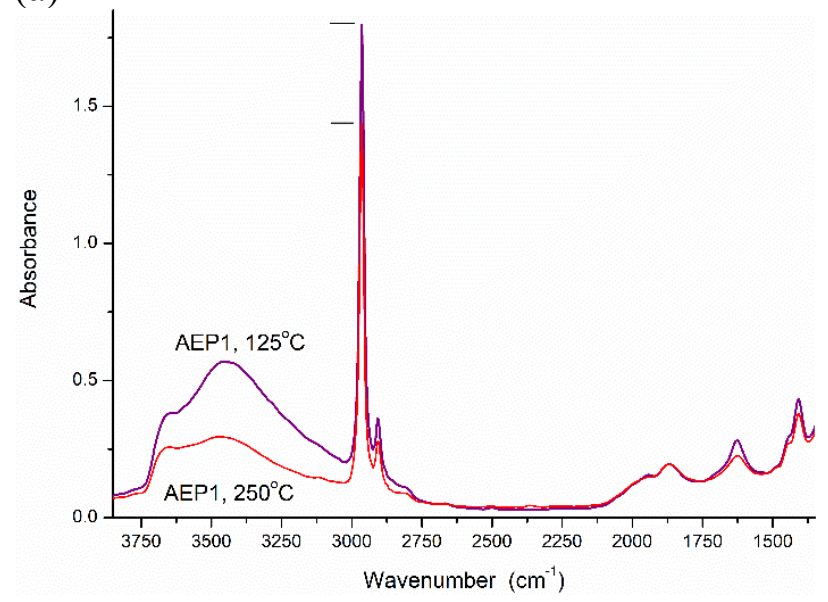

(c)

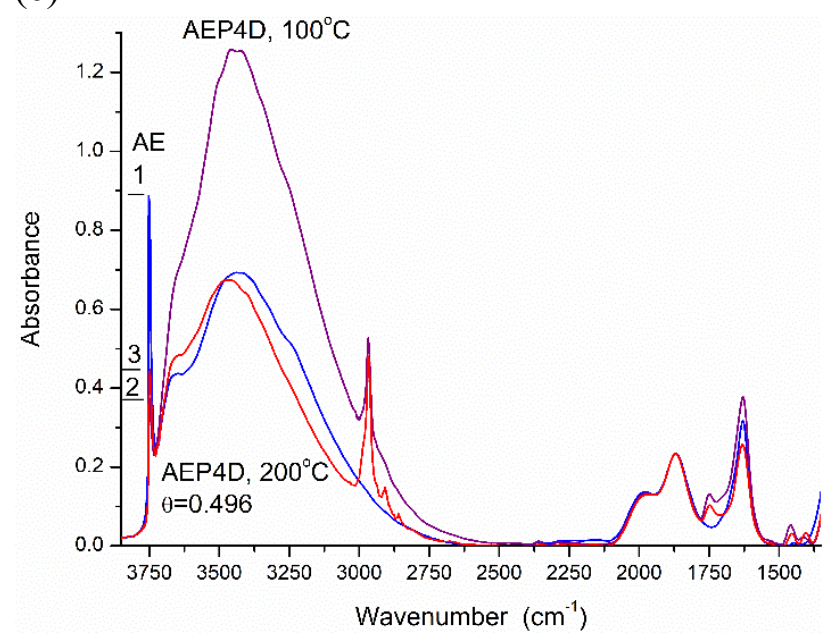

(b)

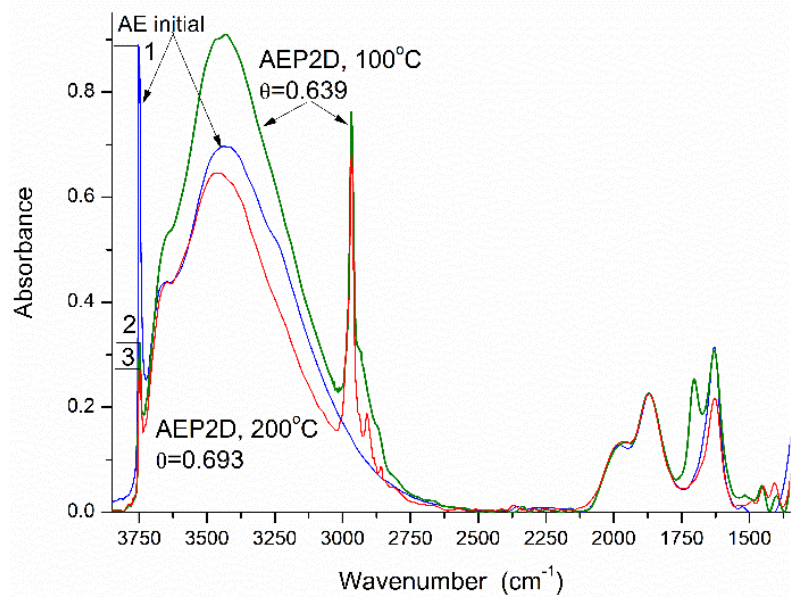

Figure S12. The IR spectra (in the 3800-1350 $\mathrm{cm}^{-1}$ range) of A-300 (AE) modified by (a) P1 at 125 ${ }^{\circ} \mathrm{C}$ and $250{ }^{\circ} \mathrm{C}$; (b) P2D at $100{ }^{\circ} \mathrm{C}$ and $200{ }^{\circ} \mathrm{C}$; (c) P4D at $100{ }^{\circ} \mathrm{C}$ and $200{ }^{\circ} \mathrm{C}$ for $1 \mathrm{~h}$. In some Figures, the values of $\theta$ (the degree of substitution of free silanols (band at $3750-3740 \mathrm{~cm}^{-1}$ ) by hydrophobic functionalities) are shown as the spectra of unmodified silica A-300 (AE).

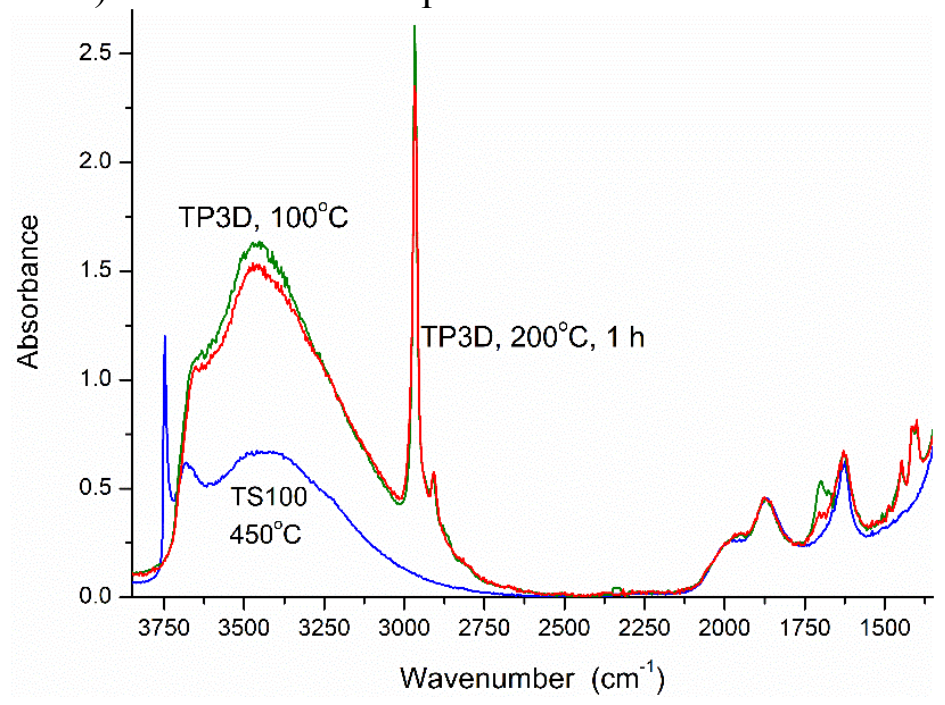

Figure S13. The IR spectra (in the $3800-1350 \mathrm{~cm}^{-1}$ range) of TS 100 unmodified (preheated at 450 ${ }^{\circ} \mathrm{C}$ ) and modified by $\mathrm{P} 3 \mathrm{D}$ at $100{ }^{\circ} \mathrm{C}$ and $200{ }^{\circ} \mathrm{C}$ for $1 \mathrm{~h}$. 


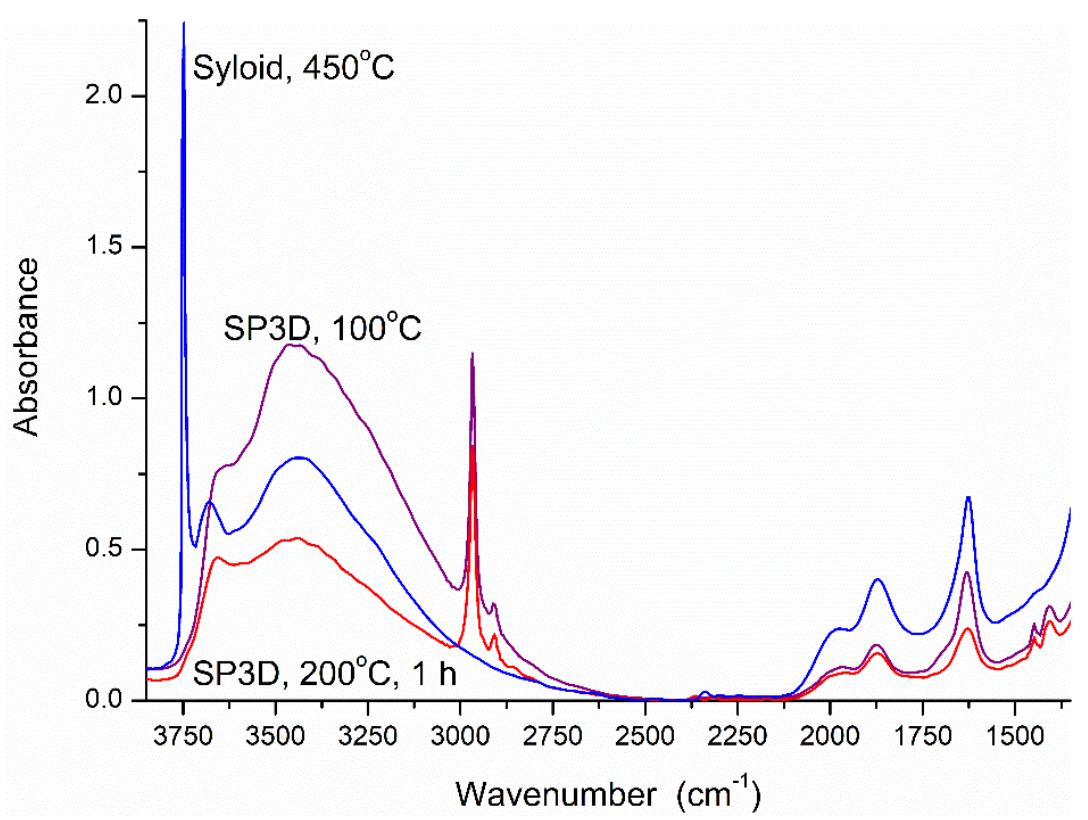

Figure S14. The IR spectra (in the $3800-1350 \mathrm{~cm}^{-1}$ range) of Syloid 244 unmodified (preheated at $450{ }^{\circ} \mathrm{C}$ ) and modified by P3D at $100{ }^{\circ} \mathrm{C}$ and $200{ }^{\circ} \mathrm{C}$ for $1 \mathrm{~h}$.

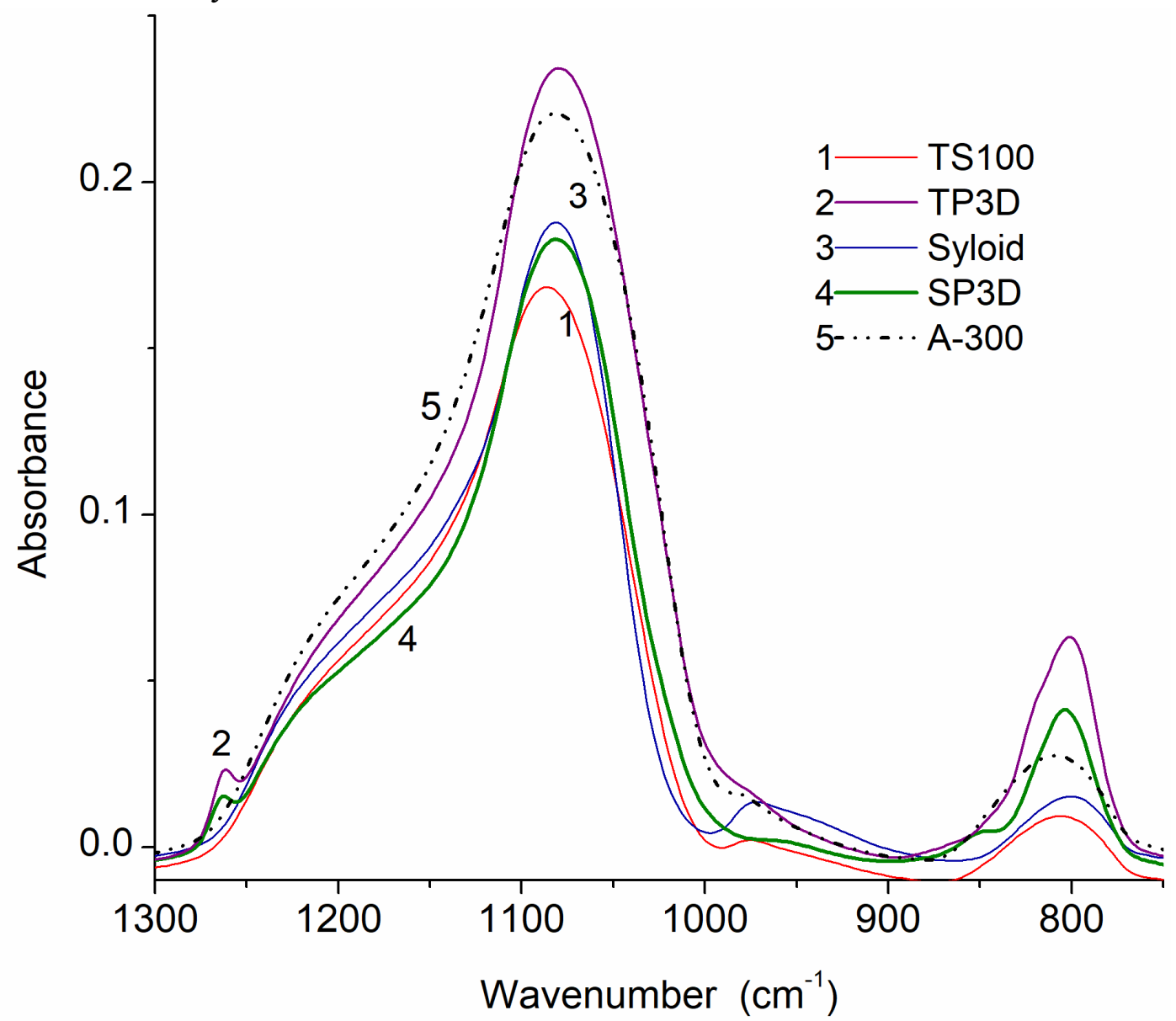

Figure S15. The ATR FTIR spectra (in the $1300-750 \mathrm{~cm}^{-1}$ range) of unmodified A-300, TS 100, and Syloid 244 and P3D modified TS 100 (TP3D) and Syloid 244 (SP3D). 


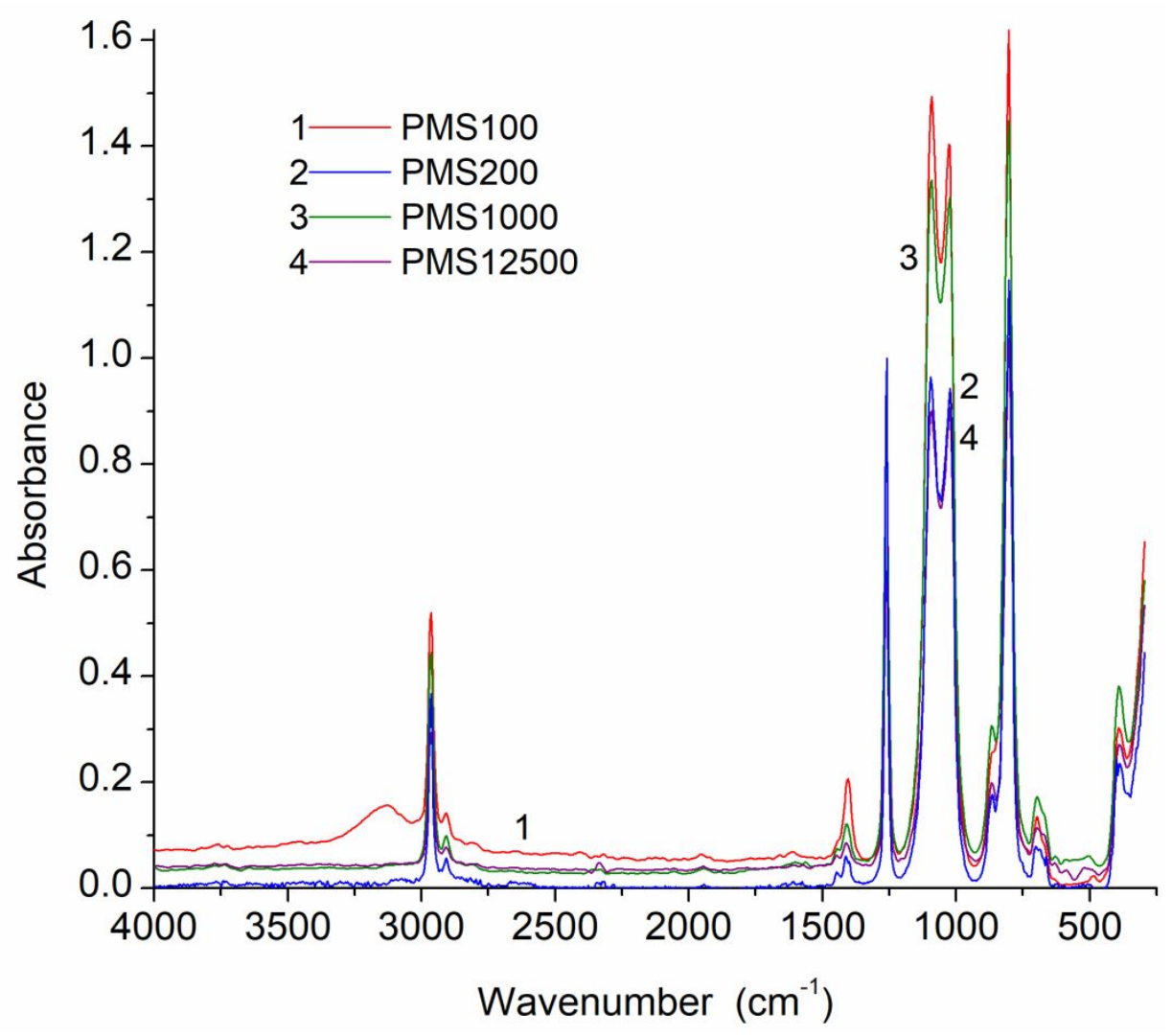

Figure S16. The IR spectra (in the $4000-250 \mathrm{~cm}^{-1}$ range) of PDMS samples alone.

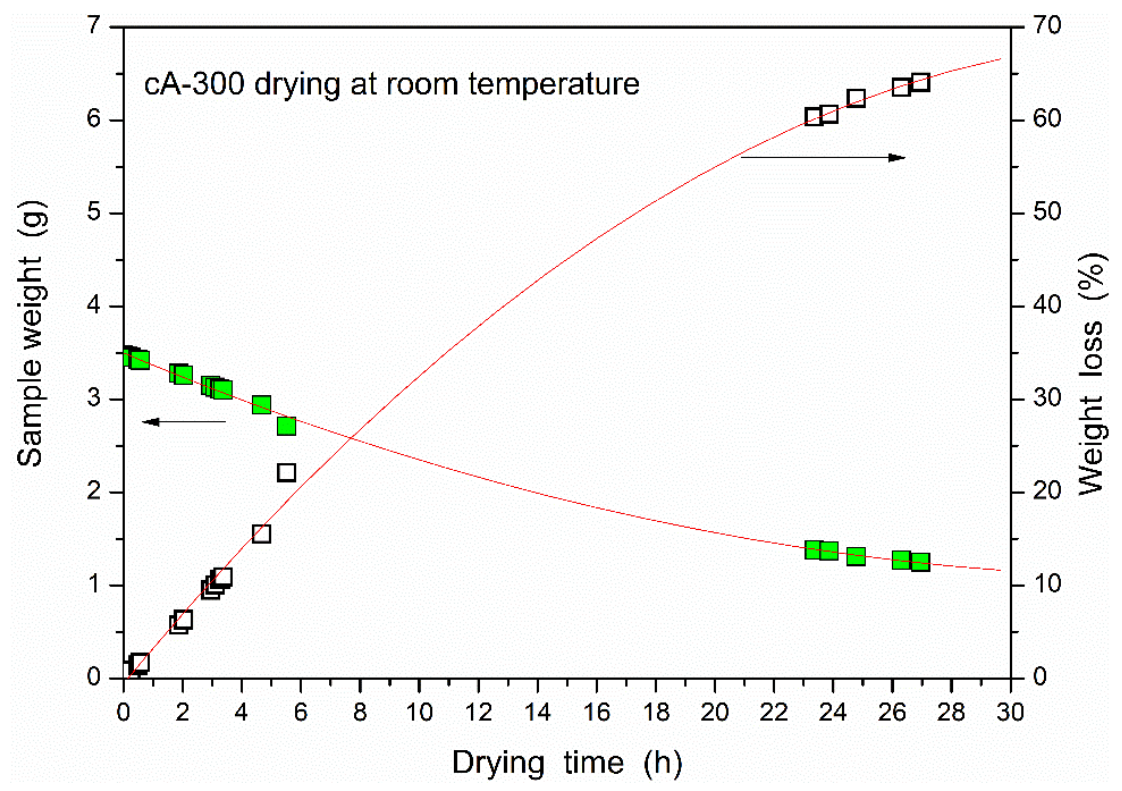

Figure S17. Weight loss due to desorption of water in air from hydro-compacted cA-300 vs. time.

\section{References}

1. A.C.M. Kuo, Poly(dimethylsiloxane), in: J. E. Mark (Ed.), Polymer Data Handbook, Oxford University Press, New York, 1999, pp. 411-434.

2. Adamson, A.W.; Gast, A.P. Physical Chemistry of Surface; Wiley: New York, 1997.

3. Gun'ko, V.M. Composite materials: textural characteristics. Appl. Surf. Sci. 2014, 307, 444454. https://doi.org/10.1016/j.apsusc.2014.04.055. 
4. Do D.D.; Nguyen, C. C.; Do, H.D. Characterization of micromesoporous carbon media. Colloids Surf A: Physicochem. Eng. Aspects 2001, 187-188, 51-71. https://doi.org/10.1016/S0927-7757(01)00621-5. 